\title{
Un futuro mejor: perspectivas e igualdad de género
}

\author{
Rosa María del Ángel Martínez
}

¿Cómo se resuelve un conflicto entre dos partes si una de ellas no cree que haya un problema, o sólo lo reconoce como uno pequeño, mientras que la otra parte ve un problema grande y continuo? Esta es sin duda la pregunta constante que se aplica a muchos temas, como el cambio climático, las interacciones ciudadano-policía y, para los efectos de este número, la paridad de género.

Todos vemos el universo a través de nuestros propios lentes. Y esa ventana al mundo está formada por la experiencia, la esperanza, las creencias, y los criterios y filtros personales. El desafío radica en descubrir cómo conciliar esas creencias arraigadas y opuestas, en aras de mejorar una situación.

En este sentido, el equipo editorial de la Revista Digital Universitaria (RDU) decidió invitar a un grupo de expertos en el tema de perspectiva de género, con la intención de que miremos a través de sus anteojos, para que nos ayuden a profundizar en las causas de estas brechas, así como saber en qué vamos respecto a violencia de género en México.

En este número especial, abordaremos, por un lado, proyectos de organizaciones civiles, como el de gendes que se especializa en la transversalidad de la perspectiva de género con enfoque en masculinidades. También conoceremos el trabajo de la organización Fondo maria, que apoya a las mujeres que buscan servicios de aborto legal y aboga por cambios a las leyes que restringen la autonomía reproductiva en México. Ambos artículos nos llevan a reflexionar sobre los desafíos de la inclusión de la perspectiva de género en las políticas públicas. 
Por otro lado, se discutirá el concepto de revictimización los mecanismos asociados con ésta, y el impacto y los riesgos para las mujeres, así como una reflexión sobre la importancia de incrementar la visibilidad de los derechos de las víctimas, y de su atención mediante la interseccionalidad y un enfoque especializado y diferencial.

Creemos firmemente que la educación es un medio para lograr un cambio social. Consideramos que las instituciones educativas pueden desempeñar un destacado papel en el logro de la igualdad de género. Es por ello, que en este número también discutiremos, por un lado, la importancia de la incorporación de la perspectiva de genero al currículo para atender la violencia de género $y$, por otro, el problema del acoso y violencia escolares en México.

Asimismo, trataremos un interesantísimo análisis de la asociación entre brujas y mujeres: ¿qué tan exacto es este estereotipo?, ¿por qué las mujeres son mucho más propensas a ser acusadas?

Es cierto que la información, en lugar de las anécdotas, siempre es útil. Aunque también ayuda reconocer que necesitamos una comprensión compartida de cada una de nuestras experiencias, si queremos cerrar las brechas en nuestra visión del mundo y hacer los cambios necesarios para mejorar la vida de todos. Pero ¿cómo podemos lograrlo? Necesitamos que la sociedad civil y las comunidades estén empoderadas y sean cada vez más audaces y valientes, para hacer lo correcto para las mujeres, las niñas y los niños, para las personas con discapacidad, los pueblos indígenas, y los grupos que durante mucho tiempo han sido marginados y excluidos.

Este número especial es una pequeña aportación a la imperante necesidad de tener datos sólidos y desglosados sobre los derechos humanos y la igualdad de género, para descubrir en dónde se encuentran las mayores necesidades y garantizar la inclusión de los que hemos dejado rezagados. La igualdad de género, los derechos de las mujeres y los derechos humanos no pueden ser valores a los que simplemente aspiramos, sino que deben considerarse como los cimientos que fundamentan a la humanidad misma. Deben servir como nuestra guía, mientras navegamos este camino hacia un futuro mejor para todos.

\section{Cómo citar este artículo}

* del Ángel Martínez, Rosa María. (2020, julio-agosto). Un futuro mejor: perspectivas e igualdad de género. Revista Digital Universitaria (RDU), 21(4). Dol: http://doi. org/10.22201/cuaieed.16076079e.2020.21.4.0 


\section{Rosa María del Ángel Martínez}

rmdelangel@outlook.com https://orcid.org/0000-0001-7655-0314

Estudió la licenciatura en Creación literaria, se ha especializado en la edición de revistas y libros electrónicos. Inició su formación profesional como becaria de la Revista Digital Universitaria (RDU), haciendo la labor de corrección de estilo y maquetación de PDFS. Posteriormente, colaboró en el Proyecto de digitalización del acervo histórico de la Revista de la Universidad de México, y en el Proyecto de digitalización del acervo histórico de la Gaceta UNAM, que corrieron a cargo del área de Acervos Digitales de la Dirección General de Tecnologías de la Información y Comunicaciones (DGTIC). Al mismo tiempo, colaboró en el Proyecto Universitario del Libro Electrónico para la Dirección General de Publicaciones y Fomento Editorial (DGPyFE), en el cual produjo y editó libros y tesis en formato ePub 2 y 3. Formó parte del equipo que estuvo a cargo del proyecto Digitalización de las Obras Completas de Francisco Hernández. Perteneció al equipo de Revistas UNAM, en donde desempeñó actividades como: configuración de la plataforma ojs 2 y 3, asesorías a editores, autores y equipos editoriales para la gestión de la plataforma y seguimiento del proceso editorial de una revista electrónica. Ha impartido talleres de producción y edición de eBook básico y avanzado como parte del Programa de apoyo a la profesionalización de la actividad editorial organizado por la DGPYFE. Actualmente funge como editora asociada de la Revista Digital Universitaria. 